\title{
Intervention by international organizations in regime complexes
}

\author{
Matias E. Margulis ${ }^{1,2}$
}

Accepted: 29 September 2020 / Published online: 8 October 2020

(C) The Author(s) 2020

\begin{abstract}
This article identifies the existence of a previously unknown but important type of selfdirected political behavior by International Organizations (IOs) that I term intervention. Intervention occurs when an IO secretariat acts with the intention of altering an anticipated decision at a partially-overlapping $\mathrm{IO}$ in a regime complex. Intervention is a distinct type of behavior by IOs that differs from either bureaucratic competition among IOs for mandates, resources and policy influence, or cooperation to achieve joint regulatory goals and enhance performance. I probe the plausibility of intervention through an analysis of three illustrative case studies in the regime complex for food security showing self-directed political actions by the secretariats of the Food and Agriculture Organization (FAO), World Food Programme (WFP) and Office of the High Commissioner for Human Rights (OHCHR) directed at altering decision-making by states at the World Trade Organization (WTO). I identify three distinct intervention strategies - mobilizing states, public shaming and invoking alternative legal frameworks - in which IOs utilize their material, ideational and symbolic capabilities to influence decision-making not within their own institutions, but at other, overlapping organizations in a regime complex over which they have no direct control.
\end{abstract}

Keywords Regime complex · International organizations · Secretariats · Organizational culture $\cdot$ International trade $\cdot \mathrm{WTO} \cdot \mathrm{FAO} \cdot \mathrm{WFP} \cdot \mathrm{OHCHR} \cdot$ Food security

CL codes

F13 Trade Policy • International Trade Organizations

F51 International Conflicts $\bullet$ Negotiations $\bullet$ Sanctions

F53 International Agreements and Observance • International Organizations

F55 International Institutional Arrangements

K38 Human Rights Law • Gender Law

Q17 Agriculture in International Trade

Q18 Agricultural Policy • Food Policy

Matias E. Margulis

matias.margulis@ubc.ca

Extended author information available on the last page of the article 


\section{Introduction}

Scholars now recognize that international organizations (IOs) do not operate in splendid isolation but are increasingly embedded in "regime complexes" in which their authority partially overlaps with other IOs and international agreements in the governance of an issue-area (Raustalia and Victor 2004; Alter and Meunier 2009; Alter and Raustiala 2018). Regime complexes matter because they can generate new, or amplify existing, political conflicts among states navigating non-integrated governance systems with diverse, and sometimes contradictory, rules, norms, and policy goals (Orsini et al. 2013; Margulis 2013; Gehring and Faude 2014; Gómez-Mera 2016). The lack of formal hierarchy among institutions in a regime complex means there is no definitive arrangement or meta-authority to which states can appeal to settle jurisdictional ambiguity or treaty conflicts (Alter and Meunier 2009; Keohane and Victor 2011; Kreuder-Sonnen and Zürn 2020).

A substantial body of scholarship has convincingly shown how states pursue their interests in regime complexes through novel "cross-institutional political strategies" (Alter and Meunier 2009:16) that range from playing overlapping international insitutions off one another to promoting harmonization among international insitutions. While this literature has significantly advanced our knowledge of the political behavior of states, it has largely overlooked the role of IOs and their political behavior in regime complexes. Despite a well-established and rich literature on IOs as actors with independent preferences and capabilities to pursue self-directed political action (Barnett and Finnemore 2004; Hawkins et al. 2006; Biermann and Siebenhüner 2009; Oestreich 2012; Bauer and Ege 2016), these insights have been largely ignored in the regime complex scholarship. ${ }^{1}$ The regime complex literature tends to treat IOs merely as the arenas in which states play out their cross-institutional political strategies, rather than as actors capable of pursuing their own interests and political objectives. This omission is surprising given that nearly all regime complexes identified to date are populated by two or more IOs that have the responsibility for implementing and upholding the overlapping rules and policies that scholars have identified as the key driver of the politics of regime complexes. The question of how IOs navigate the political dynamics of the regime complexes in which they are embedded has received inadequate scholarly attention. IOs are too important a set of actors, I contend, to be relegated to the margins of analysis of how the political dynamics of global governance are being reconfigured by the emergence of partially overlapping authority among international institutions.

In this article, I seek to fill this lacuna by demonstrating the existence of a previously unidentified type of independent political behavior by IOs in regime complexes that I term intervention. Intervention is a self-directed action by the secretariat of one IO with the purpose of altering or reversing a prospective decision at an overlapping IO in the regime complex. As I will show, intervention is a distinct type of IO behavior that differs from existing conceptions of cooperation and competition among IOs. Drawing on analysis of the regime complex for food security, I identify three cases of intervention by the Food and Agriculture Organization (FAO), World Food Programme (WFP) and Office of the High Commissioner for Human Rights (OHCHR) directed at influencing decision-making at the World Trade Organization (WTO). The three

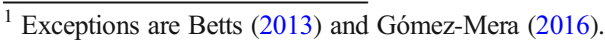


intervening IOs analyzed here vary significantly in their mandates, institutional design, capabilities and relationship to the WTO, demonstrating that a wide variety of different types of IOs engage in intervention. I identify three distinct intervention strategies mobilizing states, public shaming and invoking alternative legal frameworks - in which IOs utilize their material, ideational and symbolic capabilities to pursue externallyoriented political actions to alter outcomes at other IOs in a regime complex. I demonstrate that the FAO, WFP and OHCHR employed these intervention strategies to insert themselves into the politics of decision-making at the WTO, in an effort to ensure that international trade rules did not undermine world food security and efforts to combat hunger.

The purpose of this study is concept formation (Gerring 1999). The three illustrative case studies serve to demonstrate the existence of intervention and illuminate its key dynamics. Since this study breaks new ground by identifying an important but previously unrecognized phenomenon, it does not engage in explicit ex ante hypothesis testing. Instead, this article employs an exploratory, inductive approach that draws on evidence from the case studies to develop the concept of intervention and identify avenues for future research and theory development.

This study makes contributions to the literatures on regime complexes, IO interaction and IOs as actors. First, I demonstrate that IOs are not just part of the architecture of regime complexes, but actors that initiate and undertake their own cross-institutional political strategies in response to decisions taken at other parts of the regime complex. Second, I identify a novel type of IO interaction, intervention, that is distinct from either bureaucratic competition among IOs for mandates, resources and policy influence (Betts 2013; Morse and Keohane 2014; Lipson 2017) or cooperation to achieve joint regulatory goals and/or enhance policy effectiveness and performance (Johnson and Urpelainen 2012; Gehring and Faude 2014; Heldt and Schmidtke 2019). Lastly, I contribute to the literature on IOs as independent actors in global governance by demonstrating three novel political strategies pursued by secretariats in order to influence decision-making not within their own institutions, but at other, overlapping organizations over which they have no formal control.

The article is structured as follows. The next section situates this contribution within the relevant literature on regime complexes and IOs. Section 3 specifies the concept of intervention and theorizes the conditions that give rise to this behavior. Section 4 sets out the research design and methods. Section 5 offers a detailed empirical analysis of interventions by the FAO, WFP and OHCHR to influence decisions by the member states of the WTO. The concluding section discusses how the concept of intervention could be applied to other regime complexes and identifies directions for future research.

\section{Regime complexes and IOs}

IOs have been primarily conceptualized in the literature as components of the structure of regime complexes rather than as political actors within them. A regime complex is defined as "an array of partially overlapping and nonhierarchical institutions that includes more than one international agreement or authority" (Raustalia and Victor 2004: 279). In most theorizing on the politics of regime complexes, the principle importance of IOs lies in the fact that they are the main forums or arenas in which 
states pursue their interests by utilizing cross-institutional political strategies, such as "regime-shifting" (Helfer 2009), "institutional deference" (Pratt 2018) and "hostagetaking" (Hofmann 2019). Yet IOs are not only arenas for states to pursue their strategic goals - they can also be independent actors in their own right (Reinalda and Verbeek 1998; Barnett and Finnemore 2004; Oestreich 2012). A well-established literature spanning Principal-Agent (PA) theory and Constructivism has demonstrated that IO secretariats can develop their own preferences, enjoy (relative) independence from their member states to purse their own agendas, and utilize material and ideational resources to influence policy, with their actions driven by instrumental and/or principled objectives (Nielson and Tierney 2003; Barnett and Finnemore 2004; Hawkins et al. 2006; Nielson et al. 2006). While IOs vary considerable in terms of their independence, authority and capabilities, numerous studies have convincingly shown that IOs, including the World Bank, International Monetary Fund (IMF), World Health Organization (WHO) and United Nations Environment Programme (UNEP), have pursued independent agendas and policy goals that diverged from those preferred by their member states (Xu and Weller 2008; Weaver 2008; Chwieroth 2009; Biermann and Siebenhüner 2009; Oestreich 2012; Jinnah 2014; Johnson 2014).

Existing models of the politics of regime complexes, however, have yet to fully incorporate IOs as independent political actors. While scholars of regime complexes have taken steps to model in the behavior of private actors (Green and Auld 2017; Zelli et al. 2017) and non-governmental organizations (NGOs) (Orsini 2013; Gómez-Mera 2016), theorizing and research on IOs as actors in regime complexes has lagged behind. The likely reason is that regime complexes have been chiefly theorized by scholars working from Functionalist paradigms that view IOs as mechanisms created by states in order to lower transaction costs and solve coordination problems (Abbott and Snidal 1998); most research on regime complexes thus seeks to explain whether partially overlapping authority increases or decreases the incentives for states to cooperate (Raustalia and Victor 2004; Oberthür and Gehring 2006; Alter and Meunier 2009; Keohane and Victor 2011; Johnson and Urpelainen 2012; Orsini et al. 2013; Gehring and Faude 2014; Pratt 2018; Hofmann 2019). While this is undoubtedly important research, it has come at the cost of neglecting the agency of IOs in regime complexes. Just as we can expect the behavior of states to be shaped by the knowledge that a decision taken at one institution can unsettle, weaken and/or nullify the goals of another institution in a regime complex (Alter and Meunier 2009; Gehring and Faude 2014; Alter and Raustiala 2018), it is reasonable to expect that the behavior of IOs (as actors) may be shaped by similar dynamics. Building on the insights of PA and Constructivist theories, I posit that IOs are unlikely to be indifferent to decisions taken at other institutions in the regime complex that they expect will have negative, undesirable effects, and this may prompt them to undertake independent political action directed at altering those decisions.

Existing theories of IO interaction expect that relationships between IOs that govern similar issue-areas and whose authority overlaps will either be cooperative or competitive (Biermann and Koops 2017; Lipson 2017; Morin 2020). Cooperation among IOs can involve organizations working together toward joint policy or regulatory goals by coordinating their policies and operational activities, pooling their resources, and/or engaging in joint decision-making (Abbott and Snidal 2010; Gehring and Faude 2014; Biermann and Koops 2017). Zhao (Forthcoming), for example, demonstrates that the 
secretariats of the WTO and the Cartagena Protocol on Biosafety share information and pool expertise to prevent non-compliance by states. Conversely, competition among IO secretariats is typically characterized by rivalry for mandates, members, resources and focality (Lipson 2017; Heldt and Schmidtke 2019), but can also manifest in open conflicts over global policy influence (Morse and Keohane 2014; Hannah et al. 2017). Betts (2013:76) argues that regime complexes encourage competition among IOs because institutional proliferation provides states with more choices "in terms of which institutions they could use to address a given problem." IO secretariats have been shown to respond to competitive pressures by pursuing boundary maintenance to protect their focality (Holzscheiter 2017; Kranke 2020), forum-shifting to regain "lost" focality to other IOs (Gómez-Mera 2016) and/or working with like-minded states to supplant rival organizations by creating a new challenger institution (Morse and Keohane 2014).

Intervention, however, differs from both cooperation and competition. Unlike cooperation, intervention does not involve multiple secretariats pooling their resources, coordinating their activities or working toward a joint policy or regulatory goal, but rather one IO seeking to insert itself into the politics of decision-making at an overlapping organization in order to influence a particular outcome there. In contrast to competition, intervention is not characterized by two secretariats engaging in a zerosum game, struggling over turf, members, resources or policy influence. Instead, intervention is a political action by one IO secretariat directed at altering a specific decision at an overlapping organization. As I will show, the interventions taken by the FAO, WFP, and OHCHR were never intended to weaken the WTO or to obtain mandates or resources at its expense. In all cases, these intervening IOs affirmed their support of the WTO's mandate to establish a rules-based global trading order, but intervened in an effort to alter specific trade rules that they anticipated would have negative consequences for food security.

The concept of intervention pushes forward our theorizing of IOs as political actors. The existing literature on IOs as actors has focused on the agency of IOs to influence decisions taken within their organizational boundaries. However, in regime complexes, IOs may be concerned not only by what their own members are doing but by decisions taken at overlapping organizations in the regime complex. If IOs are not passive in the face of objectionable decisions by their member states (Barnett and Finnemore 2004; Hawkins et al. 2006; Nielson et al. 2006), it is logical to expect that they are also not indifferent to objectionable decisions taken in other parts of the regime complex. Taking IOs seriously as actors makes it reasonable to expect that they may seek to influence decisions taken outside their organizational boundaries and at overlapping organization in the regime complex, when they perceive such an external decision may have negative consequences.

The question then is how IOs seek to influence decision-making at overlapping organizations (Costa 2017). The conditions faced by IOs in regime complexes differ from those under which existing PA and Constructivist scholarship have theorized IO agency. Focusing on situations in which an IO has exclusive authority to govern an issue-area, these approaches have analyzed how an IO wields influence over the behavior of its member states by utilizing political strategies unique to the delegation relationship, including by withholding privileged information, manipulating its organization's procedural rules and decision-making processes, or by leveraging its claims to 
exclusive competence in an issue-area to engage in policy learning/socialization of its members (Haas 1989; Martin 2006; Barnett and Coleman 2005; Weaver 2008; Biermann and Siebenhüner 2009). However, this repertoire of strategies that an IO utilizes to exercise influence internally will not apply when seeking to exercise influence externally at an overlapping organization, where, for example, it does not have control over the other organization's procedures or rules and cannot claim exclusive competence. Instead, as the following analysis will show, IOs respond creatively to regime complex situations by devising distinct strategies to influence decision-making at overlapping organizations, including mobilizing states, public shaming and invoking alternative legal frameworks. This article thus makes an important contribution to scholarship on IOs as actors by advancing our understanding of how IOs seek to exercise influence outside their organizational boundaries.

\section{Intervention}

\subsection{Conceptualizing intervention}

Intervention occurs when the secretariat of an IO - its executive head or bureaucracy acts with the intention of altering an anticipated decision at an overlapping organization in a regime complex. As the existing literature on IOs as actors has shown, the executive head or bureaucracy of an IO can hold preferences that are independent of those of its member states and take self-directed actions on behalf of the organization (Barnett and Finnemore 2004; Kille 2007; Xu and Weller 2008; Hall and Woods 2018). The target of intervention is the decision-making body of the partially-overlapping organization (typically its member states). ${ }^{2}$ A decision is defined here as a choice, judgement or course of action that is reached through a formal process involving preestablished procedures and rules. Decisions result in manifold outcomes, including international agreements, regulation, policies, resolutions, financial commitments, political declarations, legal interpretation, new tasks for IOs, etc. Intervention is depicted in Fig. 1, with the intervention by the secretariat of $\mathrm{IO}^{1}$ targeting the decision-making body of $\mathrm{IO}^{2}$ represented by a transversal arrow. Clarifying the units of analysis and who is "doing the doing" helps to more clearly delineate the concept of intervention from existing work on regime complexes, much of which analyzes conflicts between partially-overlapping treaties, as well as from concepts such as cooperation that are based on interaction between secretariats.

Importantly, intervention is a self-directed action by an IO secretariat, meaning that it is: (1) unsolicited (i.e., not in response to a request from the target IO or its member states), and (2) not driven by its own member states. IOs are routinely asked to assist and support the work of other IOs, including by being granted observer status and called in as expert advisors (Haas 1989; Biermann and Siebenhüner 2009). In addition, IOs may also be periodically asked by a subset of another IO's member states to provide analysis and advice based on their expertise; the UN Conference on Trade and Development (UNCTAD), for instance, frequently receives requests for technical

\footnotetext{
${ }^{2}$ In some cases, states may choose to delegate decision-making authority (e.g., International Criminal Court, WTO dispute panels), but states retain control over key decision-making in the most IOs.
} 


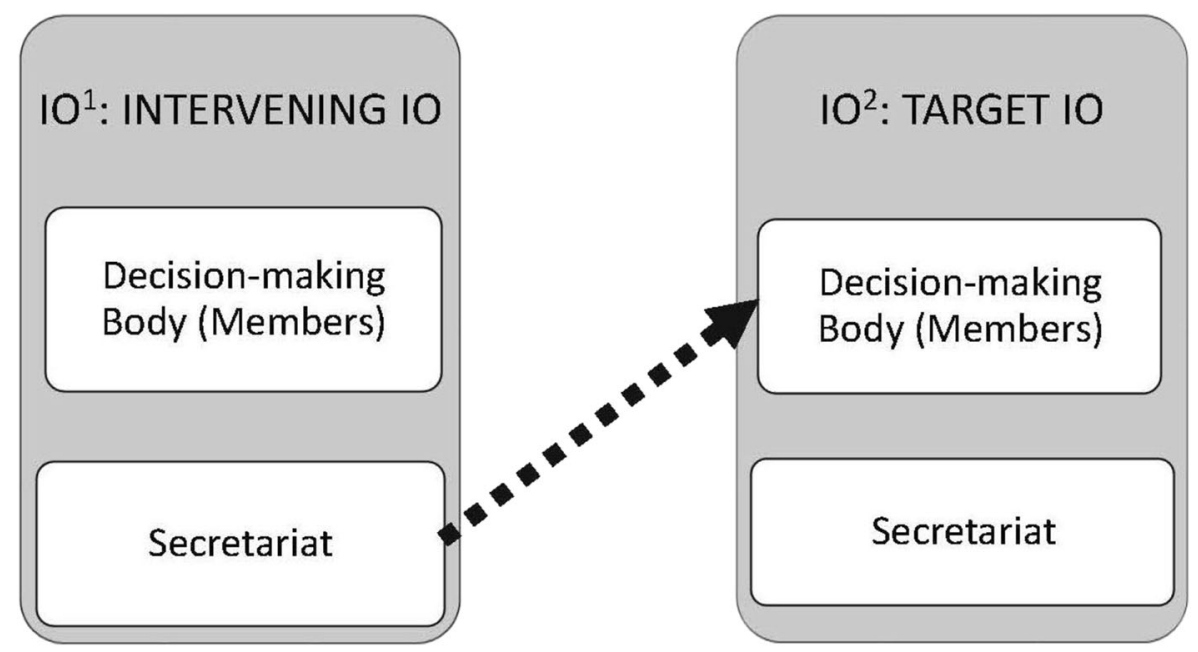

Fig. 1 IO intervention

assistance from developing countries at the WTO (Hannah et al. 2017). In contrast, however, intervention involves an IO undertaking actions that are unsolicited by states - and which may indeed be unwanted and perceived as unwelcome interference or meddling in the business of states - at the target IO. As the following cases will show, the FAO, WFP and OHCHR's interventions were self-initiated and not solicited by either WTO members or the WTO secretariat.

An alternative explanation for an IO secretariat taking action to influence a decision at another IO in a regime complex is simply that it is acting on the directions of its own member states, either collectively or a subset. Members states of the intervening IO could be dissatisfied by a decision at the overlapping organization and issue formal instructions - such as through a resolution or tabled motion - or informal guidance to the secretariat to involve itself in the work of the target IO. However, as the analysis will show, the secretariats of the FAO, WFP and OHCHR all initiated their interventions independently and were not directed - formally or informally - to do so by their member states. Indeed, in some cases, these IOs faced backlash once their members became aware of their activities to influence decisionmaking at the WTO.

What then motivates intervention? While IOs are predominantly seen as strategic and self-interested actors (Hawkins et al. 2006; Johnson 2014; Littoz-Monnet 2017), it is also recognized that the behavior of an $\mathrm{IO}$ is guided by its organizational culture (Barnett and Finnemore 2004; Xu and Weller 2008; Weaver 2008; Chwieroth 2009). An IO's organizational culture refers to "the shared ideologies, norms, and routines" that shape the secretariat's expectations about how its mandate is to be operationalized, its professional identities and values, and what behavior will be rewarded or punished (Nielson et al. 2006:109). Scholarship on organizational culture has shown that IO behavior is guided by both strategic and principled considerations; this manifests itself in how a secretariat understands the causes and solutions to international policy problems and how it responds to changes in its external environment (Barnett and Finnemore 2004; Nielson et al. 2006; Sarfaty 2009; Chwieroth 2009; 
Weaver and Nelson 2016). As the cases that follow will demonstrate, the secretariats of the FAO, WFP and OHCHR chose to intervene because they expected that a specific decision taken by WTO members would worsen world food security. Their interventions were primarily driven by principled beliefs, that is, "shared values" and "ideas about what is wrong and right" (Sikkink 1993:412), even if intervening meant challenging the interests of powerful states and risked exposing their organization to backlash. That the IOs in these three cases were driven to intervene for principled reasons does not, of course, exclude the possibility that IOs may also be motivated to intervene for more instrumental or self-interested reasons.

The cases analyzed in this study demonstrate that intervention is undertaken by a wide range of different types of IOs. The FAO, WFP and OHCHR differ from each other in important ways, including in their mandates, functions, institutional design and elemental regimes (see Table 1). These three intervening IOs stem from three distinct elemental regimes: agriculture and food (FAO), humanitarian assistance (WFP), and human rights (OHCHR). They vary considerably in their functions and mandates (Abbott and Snidal 1998): the FAO's core function is to collect and disseminate information and provide technical assistance; the WFP's primary function is to deliver international food aid; and the OHCHR's function is to elaborate human rights norms and support treaty implementation. They also vary in the nature of their membership (i.e., whether universal or exclusive) (Koremenos et al. 2001): the FAO, for example, has universal membership with 194 member states, whereas the WFP Executive Board is comprised of 36 rotating members that include both food aid donors and recipients. These IOs also vary in terms of their size and resources (Haftel and Thompson 2006; Bauer and Ege 2016; Heldt and Schmidtke 2017), how they are financed (Bayram and Graham 2017), maturity (EilstrupSangiovanni 2020) and whether they hold observer status at the target IO (Orsini 2013). As these cases show, intervention can be undertaken by IOs with both very large (WFP) and very small (OHCHR) budgets, large (FAO) and small (WFP) numbers of staff, and by comparatively older (FAO) and newer (OHCHR) IOs. These cases therefore suggest that intervention behavior is not limited to a specific type of IO, but undertaken by a diverse range of IOs.

Table 1 Institutional design features of the FAO, WFP and OHCHR

\begin{tabular}{|c|c|c|c|c|c|c|}
\hline$I O$ & Mandate & Function(s) & $\begin{array}{l}\text { Number } \\
\text { of staff }\end{array}$ & $\begin{array}{l}\text { Annual } \\
\text { budget (\$US) }\end{array}$ & $\begin{array}{l}\text { Observer status } \\
\text { to WTO }\end{array}$ & $\begin{array}{l}\text { Maturity (year } \\
\text { created) }\end{array}$ \\
\hline FAO & $\begin{array}{l}\text { Reduce hunger } \\
\& \text { improve } \\
\text { agricultural } \\
\text { production }\end{array}$ & $\begin{array}{l}\text { Produce, collect \& } \\
\text { disseminate } \\
\text { information; } \\
\text { technical } \\
\text { assistance }\end{array}$ & 4000 & $\$ 2.6$ billion & Yes & 1945 \\
\hline WFP & $\begin{array}{l}\text { Provide emergency } \\
\text { food relief }\end{array}$ & $\begin{array}{l}\text { Coordinate \& deliver } \\
\text { international } \\
\text { food aid }\end{array}$ & 800 & $\$ 5.9$ billion & Yes & 1961 \\
\hline OHCHR & $\begin{array}{l}\text { Promote \& protect } \\
\text { human rights }\end{array}$ & $\begin{array}{l}\text { Norm elaboration; } \\
\text { standard- } \\
\text { setting; treaty } \\
\text { implementation }\end{array}$ & 1200 & $\$ 250$ million & No & 1993 \\
\hline
\end{tabular}




\subsection{Scope}

This study is limited to analyzing the behavior of formal IOs, defined as an organization created by an agreement that confers international legal standing, has more than two states as members, and possesses a permanent secretariat (Pevehouse et al. 2004:103-4). The definition of IOs thus excludes informal IOs that lack a permanent secretariat, are not founded by a legal treaty, or are "explicit associations of states" (Vabulas and Snidal 2013:199), such as the G-20.

The existence of a regime complex characterized by partially overlapping authority among IOs is a necessary precondition for intervention. I propose four additional, cumulative requirements for intervention to occur. These requirements are:

1. The IO secretariat has capabilities for undertaking independent political action;

2. The IO secretariat has access to information about anticipated decision-making at the partially-overlapping organization;

3. The IO secretariat anticipates that a decision taken at the partially-overlapping organization will have negative consequences; and,

4. The IO secretariat makes an independent choice - that is, not one ordered by its member states - to undertake political action to alter the course of decisionmaking at the partially-overlapping organization.

I discuss each of these criteria in turn.

First, the capacity for independent action by an IO is essential for intervention. This means that an IO secretariat not only expresses its own preferences but also has the capabilities and will to undertake independent action in pursuit of its preferences (Bauer and Ege 2016; Lall 2017). States delegate authority to IOs to carry out specialized tasks on their behalf and empower them to achieve their mandates and missions, such as by granting secretariats the power to enforce international agreements or discretion to allocate moneys (Abbott and Snidal 1998; Nielson and Tierney 2003). Secretariats may draw on various forms of material, ideational and symbolic capabilities to pursue their own agendas and influence policy outcomes (Barnett and Finnemore 2004:19,27-29; Hawkins et al. 2006:24-25). IO secretariats vary considerably in their scope for independent action and capabilities at their disposal (Koremenos et al. 2001; Haftel and Thompson 2006; Heldt and Schmidtke 2017; Ege et al. 2019). The intervening IO secretariat must have a sufficient degree of independence in order to have the capacity to intervene.

Second, an IO secretariat will be unable to intervene if it is unaware of relevant decisions taken in other parts of the regime complex. Intervention occurs prior to a decision being made at a partially-overlapping organization, when there is still a window of opportunity for a secretariat to influence the decision trajectory. A secretariat must therefore have information about the anticipated decision in order to intervene. Secretariats routinely monitor developments at other IOs that operate in similar or overlapping policy domains (Biermann and Koops 2017; Zhao Forthcoming), which can alert them to relevant anticipated decisions. A secretariat can also learn about anticipated decisions through formal informational exchanges, as in the case when secretariats enjoy reciprocal observer status to the overlapping organization, or through other channels such as epistemic communities and 
professional networks (Haas 1989; Jinnah 2014; Littoz-Monnet 2017; Hannah et al. 2017). IOs can also invest resources to scan their environments and detect relevant information about overlapping organizations (Martin 2006).

A third criterion for intervention is that an IO secretariat expects that an anticipated decision at a partially-overlapping organization will have negative consequences. How a secretariat evaluates an external decision and whether it understands the consequences as positive or negative is partially subjective and will be "strongly influenced" by its organizational culture (Barnett and Coleman 2005:600). A secretariat must evaluate a prospective decision and judge it as harmful in order to consider intervening; this would include decisions that it views as undermining its core goals and/or against the interests and values of the international community it is tasked to uphold. We would not expect a secretariat to seek to alter a decision that it views as positive or beneficial, nor to intervene in a decision that it sees as neutral or inconsequential.

Fourth, the secretariat must independently choose to initiate an intervention, which requires deliberation by the executive head and/or senior bureaucrats to evaluate the expected harm caused by the anticipated decision, the costs of intervention and the likelihood of success. Intervention inevitably comes at a cost for secretariats because it requires expending scarce financial and human resources, and will therefore at the very least always entail an opportunity cost. Intervention also carries potential reputational costs: the behavior of IOs is "closely scrutinized" by states and is easily tarnished, making secretariats careful to avoid taking actions that could degrade their credibility and authority (Broome 2008). A particular concern for secretariats is the risk that intervention may provoke a backlash from (powerful) states. In intervening, a secretariat is seeking to alter a prospective decision arrived at by states through a formal process of inter-state bargaining and political compromise; states could view such an action as inappropriate political interference by the intervening secretariat. In choosing to intervene, the IO secretariat knowingly runs a risk of provoking a backlash from states, which could make the organization vulnerable to cuts to its budget, curtailment of its mandate, and/or other punitive measures. The secretariat must strategically weigh the potential costs of intervention against the potential benefits, while also attempting to assess the likelihood of success. It thus follows that intervention is more likely to occur the greater the anticipated negative consequences of the expected decision, the lower the anticipated costs of intervention to the secretariat, and the higher the expected chance of success.

Given these conditions, and the potential costs and risks to secretariats from intervening, it is reasonable to expect that intervention will be an episodic rather than constant occurrence in regime complexes.

\subsection{0 and regime complex characteristics}

This section specifies the characteristics of both IOs and regime complexes that we would expect make intervention more or less likely.

\subsubsection{Intervening secretariats}

Are there specific characteristics that make an IO secretariat more likely to intervene? Intervention is a type of independent political action undertaken by secretariats, and the 
existing literature has identified two factors particularly relevant to the capacity of secretariats to take actions independently of their member states: autonomy and an activist organizational culture.

A secretariat has autonomy when it is capable of designing and executing policy and advancing its goals in a manner that is insulated from states (Abbott and Snidal 1998; Reinalda and Verbeek 1998; Hawkins et al. 2006). The autonomy of secretariats has multiple dimensions, including the formal tasks they are empowered to carry out (Haftel and Thompson 2006; Bauer and Ege 2016), financial resources available to incentivize the behavior of others (Lall 2017; Heldt and Schmidtke 2017), and specialized expertise (Barnett and Finnemore 2004; Littoz-Monnet 2017; Kranke 2020). Scholars observe that secretariats with higher levels of autonomy are more able to insulate themselves from political pressure and have greater scope to take independent action to achieve their goals, including taking actions that are counter to state interests (Oestreich 2012; Lall 2017; Heldt and Schmidtke 2017; Ege et al. 2019). We should therefore expect that the greater the autonomy of an IO secretariat, the more likely it is to engage in intervention.

Secretariats with an activist organizational culture pursue agendas aligned with their core mission and goals and seek to have autonomous influence on political outcomes (Bauer 2009; Biermann and Siebenhüner 2013). Such secretariats are less risk averse to confronting states and more willing to take independent actions directed at compelling states to alter their behavior (Kille 2007; Knill et al. 2018). In sharp contrast, IOs with more deferential organizational cultures tend to be averse to challenging states and primarily concerned with securing their own survival and safeguarding their status (Knill et al. 2018). Intervention involves a secretariat taking action to influence political decision-making by states and exposes the secretariat to the risk of backlash. We should therefore expect secretariats with an activist organizational culture to be more likely to engage in intervention.

\subsubsection{Target IOs}

Are certain IOs more likely to be the target of intervention? We might expect weaker IOs - that is, IOs with limited authority, few capabilities and lacking in legitimacy - to be most targeted for intervention, since such organizations are less insulated and more permeable to outside political influence (Tallberg et al. 2013; Bauer and Ege 2016; Heldt and Schmidtke 2017). The cases analyzed here, however, suggest that powerful IOs are likely to be the target of intervention. A reason for this is that decisions issued by IOs with strong rules and wide-ranging scope have greater potential to have spillover effects elsewhere in a regime complex compared to IOs with narrow mandates and weak rules that do not produce consequential effects on other partially-overlapping IOs. We should thus expect that IOs whose mandates cut across multiple issue-areas and that make decisions with consequential outcomes are more likely to be targets of intervention.

The FAO, WFP and OHCHR secretariats all targeted the WTO. The WTO is one of the most powerful IOs; the organization is empowered with the authority to make "hard law" that is binding on states and backed by a strong enforcement mechanism, and its decisions have significant material consequences for states by creating economic winners and losers (Abbott and Snidal 1998; Steinberg 2002; Raustalia and Victor 
2004; Gehring and Faude 2014). ${ }^{3}$ The creation of the WTO in 1995, out of its predecessor, the General Agreement on Tariffs and Trade (GATT), marked a dramatic expansion in the scope and depth of global trade rules (Koremenos et al. 2001:770772). The WTO's authority goes far beyond trade, as its rules have implications for a wide range of different issue-areas, making it a "linkage machine" (Alvarez 2002). Indeed, the establishment of the WTO was an important catalyst behind the rise of regime complexes, not just the regime complex for food security analyzed in this study, but also the regime complexes for intellectual property rights (Helfer 2009; Rabitz 2014; Morin 2020), genetic resources (Raustalia and Victor 2004; Gehring and Faude 2014), and the environment (Oberthür and Gehring 2006; Jinnah 2014). The WTO's Agreement on Agriculture expanded its authority into agriculture and food, with the result that its rules have significant implications for world food security (Heri and Häberli 2011; Clapp 2015; Farsund et al. 2015). It was this potential for global trade rules to have important consequences for food security that prompted the FAO, WFP and OHCHR to seek to influence decision-making at the GATT/WTO. Notably, in all of the cases analyzed in this study, intervention was unidirectional: the secretariats of the FAO, WFP and OHCHR each intervened in the decision-making process at the WTO, but there is no evidence that the WTO secretariat has ever sought to intervene at the FAO, WFP or OHCHR.

\subsubsection{Regime complexes}

Are there attributes of a regime complex that make intervention more or less likely? The regime complex for food security encompasses partially-overlapping IOs and international agreements that govern how food is produced, distributed, and accessed at the global level (Fig. 2). It is a dense regime complex that spans multiple elemental regimes - agriculture and food, humanitarian assistance, human rights, international trade, climate change and development finance - as well as IOs with different goals (Margulis 2013; Breitmeier et al. 2020). Historically, the global governance of food security was under the remit of UN agencies, such as the FAO and WFP, which shared a common goal to end hunger (Shaw 2007). But the regime complex for food security now includes IOs with far more diverse missions and disparate goals, such as the WTO, whose primary purpose is to liberalize international trade, and the OHCHR, whose primary objective is to promote and protect human rights. While these goals may be mutually supportive in some cases, in others they may come into conflict.

IOs with similar goals are more likely to converge around shared norms, rules and values (Kreuder-Sonnen and Zürn 2020). While partially-overlapping IOs with similar goals may in some cases disagree on the particular details of policy, there is a tendency for such IOs "to minimize uncertainty by promoting similarity and coherence" (Heldt and Schmidtke 2019:1164). Conversely, regime complexes populated by multiple IOs with distinct goals are likely to have less convergence and coherence (Gehring and Faude 2014). This increases the likelihood that a decision taken at one IO may result in adverse consequences from the perspective of another IO secretariat in the regime complex and therefore prompt intervention. We would thus expect regime complexes

\footnotetext{
${ }^{3}$ While the WTO is one of the most powerful IOs, its secretariat has limited autonomy by design (Elsig 2010); the power that IOs have as institutions may differ from the power held by their secretariats.
} 


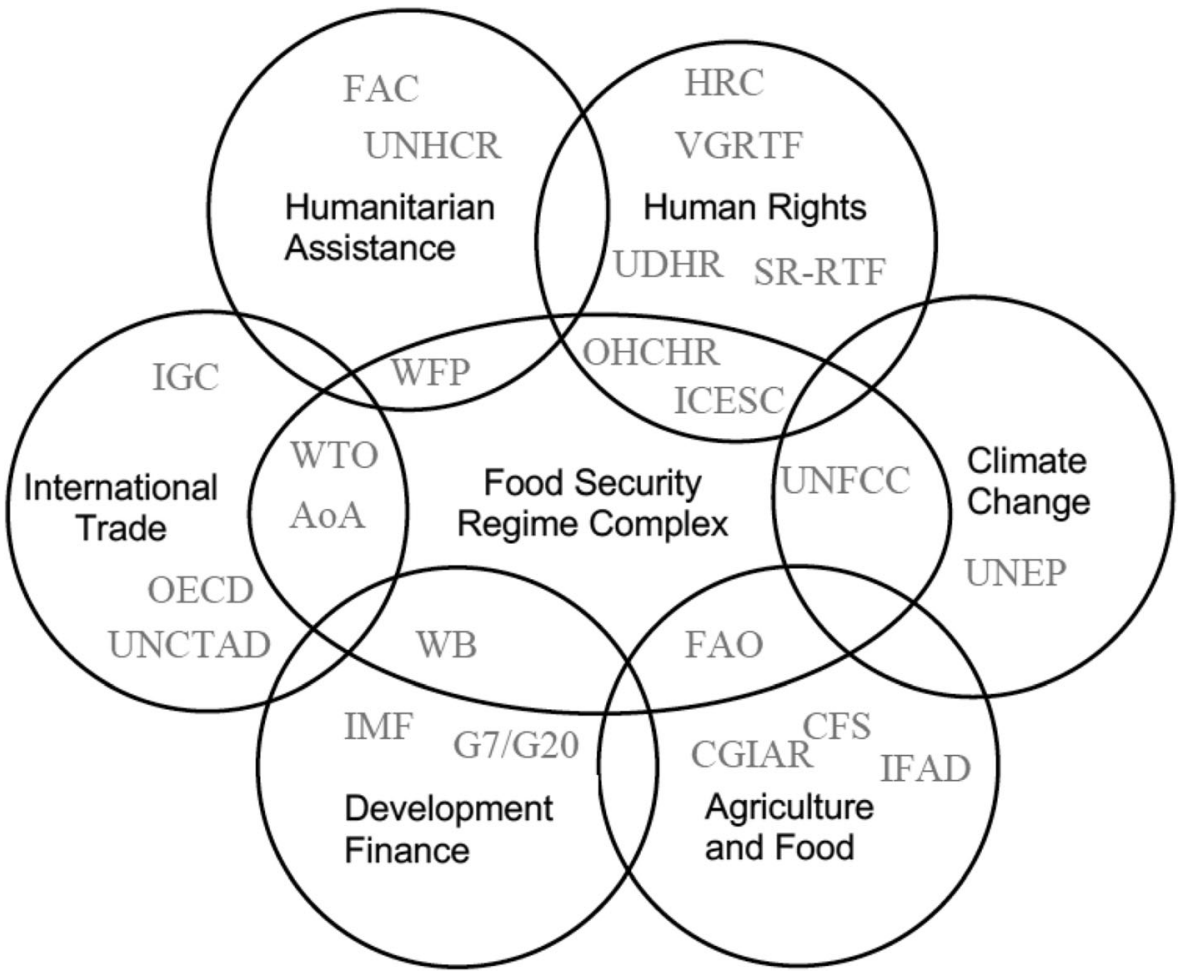

Fig. 2 The regime complex for food security. Notes: AoA = Agreement on Agriculture; CGIAR = Consultative Group for International Agricultural Research; IFAD = International Fund for Agricultural Development; HRC = Human Rights Council: ICESCR = International Covenant on Economic, Social and Cultural Rights; IGC = International Grains Council; OECD = Organization for Economic Cooperation and Development; SR-RTF = UN Special Rapporteur on the right to food; UDHR = Universal Declaration on Human Rights; UNCTAD = United Nations Conference on Trade and Development; UNEP; United Nations Environment Programme; UNFCCC = United Nations Framework Convention on Climate Change; UNHCR = UN High Commissioner for Refugees; VGRTF = Voluntary Guidelines to support the Progressive Realization of the Right to Adequate Food in the Context of National Food Security; WB = World Bank

populated by IOs with different goals to be more likely to create conditions for intervention than regime complexes characterized by IOs with similar goals.

\subsection{Intervention strategies}

Drawing on analysis of the regime complex for food security, I identify three distinct intervention strategies that can be utilized by IOs: (1) mobilizing states; (2) public shaming; and (3) invoking alternative legal frameworks. Each intervention strategy encapsulates different forms of deliberate and purposeful action by an IO secretariat and requires them to expend some combination of material, ideational and/or symbolic resources. A secretariat will choose the intervention strategy that it believes has the greatest chance of success, best corresponds with its existing capabilities, and/or minimizes political backlash. These intervention strategies are not mutually exclusive, as a secretariat could feasibly utilize two or more strategies simultaneously, or in a sequential manner, depending on the situation and constraints it faces. Nor is this 
necessarily an exhaustive list of intervention strategies, but intended as a starting point for understanding the political behavior of IOs in regime complexes.

Mobilizing states occurs when the intervening secretariat enrolls member states of the target IO and steers them towards actions intended to alter the outcome of decisionmaking. Working with and through member states in the target $\mathrm{IO}$ - who have the right to debate and vote on decisions there - provides the intervening secretariat with a means to influence the decision-making process in an organization over which it has no direct control. Mobilizing states involves the intervening secretariat taking an unsolicited and de facto leadership role in coordinating states to enhance their bargaining effectiveness, engaging in problem definition and proposing policy solutions, and devising political strategy to advance their shared objectives. Mobilizing states at the target IO is possible because behind most decisions, there is a heterogeneity of state preferences and varying power capabilities (Nielson and Tierney 2003; Hawkins et al. 2006; Haftel and Thompson 2006). The intervening secretariat can enlist dissatisfied states at the target IO by offering strategies to alter the anticipated decision, specialized information, and resources (such as staff time, capacity, and expertise) to help achieve their mutual goals. Such leadership will be especially attractive for less well-resourced or weaker states at the target IO. It is reasonable to expect that states will agree to defer to, and be steered by, the intervening secretariat if they believe that doing so will enhance their political effectiveness and ability to influence the decision-making process. Directly mobilizing member states of the target IO to obtain an indirect channel to influence decision-making is distinct from situations when IOs build coalitions with actors such as NGOs to raise issue awareness (Gómez-Mera 2016). Mobilizing states is also different from "orchestration" by IOs (Abbott and Snidal 2010), since the intervening secretariat enrolls states rather than non-state actors, and its goal is to alter a decision at a partially-overlapping organization rather than to collaborate with other organizations to enhance its own functional performance.

Public shaming involves the intervening secretariat exerting its moral authority (Barnett and Finnemore 2004:23) to present the prospective decision at the target IO as a violation of appropriate behavior, with the intervening secretariat positioning itself as the defender of the values of the international community. Public shaming has similarities to the practice of "naming and shaming" by the UN and NGOs to bring attention to a state's violation of international norms and urge reform (Lebovic and Voeten 2006; Gaer and Broecker 2013). But in the context of intervention, public shaming involves the intervening secretariat presenting a collective decision by the member states of the target IO as unethical and wrong, rather than singling out a particular state. The purpose of public shaming is to generate international opprobrium against the anticipated decision at the target $\mathrm{IO}$ in order to pressure its member states to change course. To carry out this intervention strategy, the intervening secretariat must articulate and communicate to international audiences why the decision is at odds with a widely-held value(s) of the international community. Public shaming is predicated on the assumption that most states care about their reputations and international standing (Lebovic and Voeten 2006), and may thus be potentially responsive to such criticism.

Invoking alternative legal frameworks occurs when the intervening secretariat claims that the anticipated decision at the target IO is likely inconsistent with, or in violation of, existing international law. Invoking an alternative legal framework is distinct from an intervening secretariat taking formal juridical action, such as bringing 
a case to an adjudicating body. Instead, an intervening secretariat invokes an alternative legal framework when its purpose is to create the perception of potential rule inconsistency and thereby put the question of the legal implications of the anticipated decision up for political debate at the target IO. Creating a perception of potential rule inconsistency may lead to uncertainty among the members of the target IO about whether the decision will result in a violation of their existing commitments under the invoked international agreement or produce a treaty conflict (Ratner 2011; KreuderSonnen and Zürn 2020). Given that states favor being in compliance with their international legal obligations (Simmons 2000) and that resolving treaty conflicts is "notoriously difficult" (Raustalia and Victor 2004:300), the uncertainty created by invoking an alternative legal framework may prompt states to revisit the correctness of the decision. This intervention strategy makes most sense when all or the majority of the members of the target IO are parties to and bound by legal commitments under the invoked agreement.

\section{Research design, cases, and methods}

The purpose of this study is to demonstrate the existence of intervention as a form of political behavior by IOs in regime complexes. It probes the plausibility of the intervention concept through an analysis of three illustrative cases in the regime complex for food security: intervention by the FAO during the GATT Uruguay Round (which established the WTO and its rules) and by the WFP and OHCHR in the WTO Doha Round. Multiple cases of intervention provide a significantly higher threshold of evidence than a single case, and demonstrate that this phenomenon is not merely a oneoff occurrence or aberration but happens with enough frequency to warrant greater attention. The cases also demonstrate that intervention has occurred in different points over time, undertaken by different IOs that vary in function, institutional design, resources, elemental regimes, and focality in the regime complex. While these are not the only instances of intervention by IOs in the regime complex for food security at the GATT/WTO, the selected cases highlight three distinct intervention strategies: mobilizing states by the FAO, public shaming by the WFP, and invoking alternative legal frameworks by the OHCHR. ${ }^{4}$

The analysis is based on field research conducted at the WTO, FAO, WFP and OHCHR in Geneva and Rome. I collected, analyzed and triangulated between multiple source of data to identify and understand the context, motivations and processes by which secretariats pursued intervention. Data analyzed in this study included official documents - such as reports, speeches, formal decisions, minutes of meetings, and internal memoranda - produced by the secretariats and member states of the GATT/WTO, FAO, WFP and OHCHR. The archival and documentary analysis was supplemented with 85 in-depth elite interviews. Interviews were semi-structured, conducted in-person or by video conference, and between one to two hours in length. Selected through purposive sampling, interview respondents included current and former senior international bureaucrats and executive heads of the FAO, WFP,

\footnotetext{
${ }^{4}$ Both the UN Special Rapporteur on the Human Right to Food and the FAO, for example, also intervened in the WTO Doha Round negotiations.
} 
OHCHR and GATT/WTO who directly participated in, or were knowledgeable about, the interventions analyzed in the study. Additional interviews were conducted with current and former member-state representatives at these IOs, as well as officials from other IOs with observer status at the GATT/WTO, such as the World Bank and UNCTAD. To address the potential for respondent bias to skew the data, I triangulated between multiple interview respondents to verify statements and ensure an accurate account of events.

\section{Interventions by the FAO, WFP and OHCHR at the GATT/WTO}

In this section, I analyze actions by the secretariats of the FAO, WFP and OHCHR intended to influence decision-making at the GATT/WTO. Despite these three IOs varying considerably in mandates, functions, and their focality in the regime complex for food security, their secretariats each chose to intervene at the GATT/WTO in an effort to alter a decision they expected would worsen world food security.

\subsection{The FAO mobilizes GATT members}

The first case demonstrates intervention by the FAO secretariat during the GATT Uruguay Round (1986-1994) of trade negotiations, which created the WTO Agreement on Agriculture. FAO officials were motivated to intervene due to their concern that proposed new agricultural trade rules would exacerbate hunger in developing countries. They mobilized and steered a group of GATT members to channel new trade rules intended to protect food security onto the negotiating table.

The FAO was established in 1945 and mandated to end world hunger by improving agriculture production in developing countries and coordinating the world's food resources. Its mission to end hunger continues to strongly shape the FAO's organizational culture, especially the identity and professional values of its staff (Christoffersen et al. 2008). Over the course of its history, the FAO has had several highly activist Director-Generals, who transformed the organization from a technical body into a vocal advocate for the world's hungry (Shaw 2007). During the tenure of Director-General Edouard Saouma (1976-1993), which corresponds to the period analyzed in this case study and who was known for his activist and confrontational leadership style, the FAO championed the interests of the Third World (Shaw 2007) and launched major policy initiatives without prior consultation or the full consent of the FAO membership (Davies 2013). The FAO secretariat has had a longstanding cooperative relationship with the GATT/WTO and holds observer status.

Launched in 1986, the Uruguay Round was intended to liberalize trade in agriculture and food, with states negotiating the new WTO Agreement on Agriculture that would set out the rules governing international agricultural trade. The FAO secretariat was a vocal supporter of the Uruguay Round, having long argued that the US and European Union's (EU) protectionist farm policies distorted the international market for agricultural trade (FAO 1986). The expert consensus was that reform of rich country farm subsidies would greatly improve global economic welfare: it was projected that taxpayers in rich countries would receive a $\$ 200$ billion "financial dividend" from cutting farm subsidies and 
developing countries would earn an additional $\$ 900$ million in farm exports (World Bank 1986).

However, while the FAO secretariat supported subsidy reform, as the negotiations progressed, it became increasingly concerned about the potential negative effects for food security. ${ }^{5}$ FAO studies estimated that the proposals at the GATT to cut rich country farm subsidies would increase world food prices, resulting in a $20 \%$ rise in the food import bills of net-food importing developing countries (NFIDCs) and reduced food consumption among poor households (FAO 1987). NFIDCs depended on cheap, subsidized imports of staple foods, such as wheat, from rich countries and were therefore expected to be the major losers from the negotiations. While a large portion of the GATT's membership - 90 out of 123 members - were NFIDCs, they were weak actors in the negotiations. The most powerful players - the US and EU - dominated the negotiating agenda and proposal development process (Steinberg 2002). Most NFIDCs lacked full-time representation in Geneva and the technical capacity to effectively participate in the negotiations (Narlikar 2003). Moreover, their diverse economic interests and lack of political unity rendered them "incapable of articulating a common line, much less of pursuing it aggressively from a position of strength" (Walch 2003:170). As a result, the NFIDCs lacked a coherent negotiating strategy and instead focused on making broad political statements, such as that the agriculture negotiations were a threat to their national sovereignty and political stability, rather than submitting concrete bargaining proposals, which is essential to engage effectively in multilateral trade negotiations (Narlikar 2003:150-153).

Senior FAO officials felt, what they described as, "a professional and moral responsibility" to take a more active role to protect the food security interests of NFIDCs at the GATT. ${ }^{6}$ However, its official observer status stipulated that the FAO secretariat was bound to remain neutral and not take any action that could "prejudice the negotiation positions of GATT member states" (GATT 1987:5). Indeed, the FAO had been explicitly warned against interfering by certain powerful GATT members, notably the US, EU, Canada and Australia, who communicated that it would be "inappropriate" and "exceed the FAO's mandate" for the organization to involve itself in sensitive trade negotiations among sovereign states (FAO 1987:45). Rich countries were dissatisfied with the FAO's activist leadership and FAO officials took the warning seriously given that these states had already threatened to cut the FAO's budget and exit the organization (Lall 2017; Knill et al. 2018). Despite the risk of backlash, however, the FAO secretariat choose to insert itself into the politics of decision-making at the GATT. This was initiated by the FAO secretariat without any request or direction from its member states. Senior FAO mangers discussed the matter internally and, with the approval of the FAO Director-General, made protecting the food security of NFIDCs at the GATT a top priority (FAO 1991:521-22).

The FAO secretariat chose a pragmatic course of action - its involvement at the GATT would be strictly behind the scenes in order to avoid a direct confrontation with rich countries. FAO officials concentrated their efforts on using the organization's resources to strengthen the bargaining capacity and effectiveness of NFIDCs. To facilitate this, the FAO permanently stationed staff in Geneva to take on the role of

\footnotetext{
${ }^{5}$ Interviews with FAO Division Deputy Director and Senior Economists, October 2008.

${ }^{6}$ Interviews with FAO Assistant Director-General and Division Director, February 2009.
} 
coordinating the work of NFIDC trade negotiators. FAO officials organized and led strategy sessions for NFIDC trade negotiators, at which FAO officials presented econometric analyses of the impact of rich countries' proposals and proposed solutions to address the potential problem of higher food import bills (FAO 1993a). NFIDC trade negotiators welcomed the FAO's involvement, knowing this would enhance their bargaining capacity given their weak position at the GATT. ${ }^{7}$ The FAO went beyond merely providing technical assistance to NFIDC trade negotiators to steering their strategy in the negotiations. For example, in the lead up to the 1988 GATT Ministerial Conference, FAO officials persuaded NFIDC trade negotiators to present the problem of higher future food prices as a balance of payment problem and to demand new multilateral financing to address this problem. This framing proved successful in convincing trade ministers to put the issue of NFIDC food import bills on the agenda of the agriculture negotiations (GATT 1988).

In spring 1989, the GATT agriculture negotiations shifted into a critical stage of bargaining focused on finalizing the design of the Agreement on Agriculture. Proposals put forward by rich countries, however, did little to address NFIDC and FAO officials' concerns about the risks to food security (GATT 1989). By this point, for over two years, NFIDC trade negotiators had failed to produce a bargaining proposal of their own due to internal divisions and the lack of technical capacity (Walch 2003; Narlikar 2003). Troubled that NFIDCs were floundering in the agriculture negotiations, FAO officials stepped in to lead the development of a bargaining proposal. FAO officials formulated a proposal containing pro-food security trade rules and presented this strategy to NFIDC trade negotiators. ${ }^{8}$ This included demands for additional food aid, monetary compensation, support for agricultural research and infrastructure, and the creation of a new multilateral fund to offset the costs of higher food import bills. Many of the FAO's proposed solutions reflected long-held policy preferences of senior FAO officials; for example, the proposal for a new multilateral fund had been advocated earlier by Saouma in 1979 as part of his failed Food Security Assistance Scheme (FAO 1979). NFIDC trade negotiators deferred to FAO officials to hold the pen and draft the bargaining proposal. In interviews, FAO officials described this active role as "inevitable" and NFIDC trade negotiators stated that it "made sense for [FAO officials] to do the drafting of the bargaining proposal" due to their in-depth knowledge of agricultural trade policy. ${ }^{9}$

As a result of the FAO's involvement, the NFIDCs tabled their first bargaining proposal at the GATT in November 1989 (GATT 1989). The proposal was notable for its technical sophistication, which included a new methodology for measuring the negative impacts of trade reforms on food security using historical trade data compiled by the FAO. The 1989 NFIDC proposal - conceived and written by FAO officials became the basis for negotiations on rules to address food import bills at the GATT. FAO officials subsequently led the drafting of two additional NFIDC proposals to further elaborate how to operationalize the measures proposed to offset the costs of higher food import bills (GATT 1990b, 1990a). The NFIDC proposals proved highly

\footnotetext{
${ }^{7}$ Interviews with Developing Country Trade Negotiators, December 2008, February, April, June 2009, and September 2019.

${ }^{8}$ Interview with FAO Division Director, February 2009.

${ }^{9}$ Interviews with Developing Country Trade Negotiators and FAO Division Director, December 2008, February, April, June 2009, and September 2019.
} 
significant, as most of the provisions formulated by FAO officials were eventually accepted by rich countries and incorporated into the WTO Agreement on Agriculture as the Decision on Measures Concerning the Possible Negative Effects of the Reform Programme on Least-Developed and Net Food-Importing Developing Countries (FAO 1993b:2-3; WTO 1994).

The FAO secretariat acted in a self-directed manner in choosing to insert itself into the politics of decision-making at the GATT. It did so by mobilizing NFIDC trade negotiators and leading them in formulating a bargaining strategy and drafting negotiating proposals. Only under the FAO's guidance did the NFIDCs become an effective negotiating bloc at the GATT. There is no evidence to suggest that FAO officials were instructed formally by the FAO's member states to mobilize NFIDCs at the GATT or lead them in developing their negotiating position and proposals. Any such instructions would not only have raised objections by rich countries, but also would have been grounds for the FAO to be stripped of its observer status to the GATT. FAO officials chose to intervene in the GATT negotiations despite clear signals from rich countries that doing so could result in backlash. Driven by its mission to end hunger, the FAO secretariat intervened of its own accord due to concerns that new disciplines on agricultural subsidies would worsen food insecurity in import-dependent developing countries. Importantly, FAO officials were not seeking to increase their resources or expand their own organization's mandate at the expense of the GATT/WTO; their intervention was not designed to have these effects, nor did it. Instead, by working with and through NFIDC trade negotiators, the FAO secretariat intervened in GATT negotiations in an effort to shape the design of global trade rules to protect world food security.

\subsection{The WFP publicly shames WTO members}

The second case analyzes intervention by the WFP secretariat at the WTO using the strategy of public shaming. The WFP is a humanitarian agency that coordinates and delivers international food aid in emergency situations, feeding approximately 90 million people annually at risk of malnutrition and starvation. It has observer status at the WTO, and WFP officials represent the organization at WTO committee meetings and have discretion to convey the organization's views to WTO member state representatives. The WFP secretariat routinely cooperates with the WTO secretariat by providing information and statistics on food aid volumes to inform technical work and negotiations.

The WTO's Agreement on Agriculture includes rules to prevent the misuse of food aid as a hidden agricultural export subsidy. These rules became subject to renegotiation with the launch of the Doha Round in 2001. Competing agricultural exporters, such as the EU, Canada, Australia, Argentina and Brazil viewed the negotiations as an opportunity to discipline the US Food for Peace Program, which requires the American government to provide the majority of its international food aid in the form of domestically-produced agricultural commodities that are processed, bagged and transported by US-based firms. This US food aid policy has long been critiqued for giving American grain exporters an unfair trade advantage and became a "bargaining chip" in the highly politicized Doha negotiations (Clapp 2015:129). There was wide support among WTO members to discipline US food aid by imposing new rules that 
would prohibit "in-kind" food aid and allow governments to provide food aid only in the form of cash donations, which is the practice of most donors.

WFP officials closely monitored the negotiations. In principle, the WFP preferred donations of cash rather than in-kind commodities, because the former is a more efficient and cost-effective mode of procuring and transporting food aid in emergency situations (Shaw 2007). However, WFP officials were alarmed by the humanitarian implications of the WTO's proposed new food aid rules, which they feared would significantly cut the supply of international food aid without any assurance to make up the shortfall with other resources. ${ }^{10}$ The US is the single largest food aid donor, and the WFP estimated that the proposed WTO rules would result in a $25 \%$ drop in food aid donations. ${ }^{11}$ The prospect that new WTO rules could induce a massive reduction of food aid concerned the WFP senior leadership, especially given that donations had already fallen in 2004 by nearly $40 \%$, leaving the organization struggling to meet the needs of a growing number of humanitarian emergencies around the world (Clay 2006). WFP officials were also concerned that the proposed rules would undermine their efforts to attract donations from new middle-income donors, who, due to their lower level of economic development, were more likely to provide in-kind food aid rather than cash donations (WFP 2005a). The WFP's Executive Director, James Morris, summed up the organization's position at the time as follows, "[t]he issue for WFP is simple. We need more resources - cash and food - to feed the growing number of hungry, seriously at-risk people" (WFP 2005a).

The WFP's Geneva-based officials communicated their organization's concerns about the proposed rules in a series of bilateral meetings with WTO member state representatives. In addition, the organization held a series of high-level briefings with WTO representatives, including flying in the WFP Executive Director from Rome to make the case for rethinking the proposed food aid rules. At a meeting held in May 2005, Morris told WTO members that he supported the goals of trade liberalization and was not there to tell them "what kind of disciplines you should place on food aid from a commercial perspective" but that as the WFP Executive Director he had a mandate to prevent any unintended consequences that could impede the fight against hunger (WFP 2005b). The WFP offered to work with WTO members to help them design food aid disciplines to create "a firewall between commercial food transactions and food aid" and achieve a "win-win" solution; however, Morris stressed that the WFP was "absolutely opposed" to any WTO rules that would discourage donations of commodities by new and traditional donors and potentially cut off hungry people from life-saving food aid, which the WFP warned "would be both a moral and public relations disaster for the WTO” (WFP 2005a:2,6).

However, while some WTO member state representatives privately acknowledged that the proposed rules could negatively affect food aid supply, the political dynamics of the negotiations were such that the EU and Canada refused to reduce their own agricultural export subsidies - a key goal of the negotiations - without concessions from the US on food aid (WTO 2005:8). Seeking a political end game to the agricultural negotiations, the draft agriculture agreement submitted to trade ministers

\footnotetext{
${ }^{10}$ Interview with WFP Director, December 2008.

${ }^{11}$ Interview with WFP Senior Economist, March 2009.
} 
for approval at the 2005 Hong Kong Ministerial thus included the proposed rules banning in-kind food aid.

At this point, Morris and other senior WFP officials recognized that they had failed to persuade WTO members to change track on the proposed food aid rules. ${ }^{12}$ WFP officials believed that if trade ministers approved the proposed rules it would have disastrous consequences for world food security. Having exhausted all other alternatives, the WFP took the extraordinary step of publishing an advertisement in the Financial Times on the opening day of the 2005 WTO Ministerial. Emblazoned with the title "Will WTO's negotiators take the food out of their mouths?", the WFP advertisement depicted four starving children followed by the message: "Trade reform is good, but restrictions on donations of food aid to the United Nations could leave these children hungry. Sadly, millions who rely on food aid to survive have no voice at the negotiating table in the Doha Round. Who will fight for them?" (WFP 2005c).

The WFP's message was unmistakable - WTO members were depicted as recklessly endangering the lives of vulnerable and hungry people. The WFP employed a strategy of public shaming in the hope that going public with its concerns, and exercising its moral authority as the UN agency charged with feeding the world's hungry, would trigger public outrage and pressure WTO member states to change course. ${ }^{13}$ The advertisement ignited international controversy as the world's media ran with coverage that the UN was claiming the WTO wanted to starve millions of innocent children (Clapp 2015). The WFP's claims were a public relations disaster for the WTO and seen to reinforce the perception that trade was skewed against the interests of the global poor.

The efforts by senior WFP officials to alter food aid rules at the WTO were selfinitiated; they did not consult the WFP's Executive Board or receive any direction from states prior to taking action. ${ }^{14}$ On the contrary, most of the WFP's Executive Board members and largest donors - including the EU, Canada, Australia, and New Zealand supported the WTO prohibition on in-kind food aid and would have likely taken action to stop the WFP secretariat from intervening had they been aware of its plans to publish the advertisement. Instead, Morris exercised his discretion as head of the WFP to insert the organization into the politics of decision-making at the WTO. Trade ministers attending the 2005 Ministerial had no advance warning about the WFP's advertisement and were caught off guard by the controversy it generated (Heri and Häberli 2011). Indeed, many trade ministers were incensed at the WFP for so publicly and directly "lobbying on a sensitive WTO negotiating issue" (Khor 2005). The EU, for instance, the WFP's second largest donor, condemned the WFP's actions as "shocking" (Mandleson and Fisher Boel 2005).

The WFP's intervention at the WTO was primarily driven by the principled beliefs of its staff and the mission of the organization to feed the hungry and avoid the preventable loss of life. Its actions cannot be explained simply as self-interested: while the proposed trade rules would have decreased the supply of international food aid, this would have been of no consequence to the WFP's authority, survival or budget, which

\footnotetext{
${ }^{12}$ Interview with WFP Director, March 2009.

${ }^{13}$ Interviews with WFP Country Director and Senior Economists, March 2009.

${ }^{14}$ Interviews with WFP Directors, Deputy Directors and Executive Board Members, October 2008 and February 2009.
} 
is financed through voluntary financial contributions from states, not through in-kind food aid. ${ }^{15}$ The choice to publicly shame the WTO was a calculated risk by the WFP secretariat, who were acutely aware that vilifying WTO members was not only controversial, but a highly political act that could harm the economic interests of powerful states. In fact, the EU later blocked Morris' reappointment for a second term as WFP Executive Director, in a move widely regarded as retaliation for his intervention at the WTO Hong Kong Ministerial. ${ }^{16}$ Nevertheless, however, when the WTO finally agreed to new rules on export subsidies in the 2015 Ministerial Decision on Export Competition, the rules did not prohibit in-kind food aid.

\subsection{The OHCHR invokes international human rights law}

The third case analyzes intervention by the OHCHR based on invoking an alternative legal framework. The High Commissioner for Human Rights is the UN's senior human rights official, responsible for promoting human rights, implementing and monitoring states' human rights obligations, and managing a secretariat, the OHCHR (UN 1994). The High Commissioner straddles many roles, including manager, politician, diplomat, norm generator, and "moral conscience" for the world (Gaer and Broecker 2013). While the office lacks judicial enforcement powers and is severely underfunded, the High Commissioner enjoys significant discretion and independence due to an ambiguous, open-ended mandate and the moral authority associated with the position (Seiderman 2019). Following the 1996 World Food Summit, at which states tasked the OHCHR to clarify their obligations in regard to the right to food under international human rights law, a number of international legal instruments were established to protect the right to food, which have encouraged issue-linkage between human rights and food security. ${ }^{17}$ Within the regime complex for food security, the OHCHR diffuses the norm of food as a human right, leads human rights "mainstreaming" across the UN system, Bretton Woods institutions and regional organizations, and monitors the coherence of states' policies with their commitments under human rights treaties. Unlike the FAO and WFP, the OHCHR does not have observer status at the WTO; however, it has a team in its Special Procedures and Right to Development Division that monitors developments at the WTO and cooperates with the WTO secretariat on an ad hoc basis. ${ }^{18}$

Following the launch of the Doha Round agriculture negotiations in 2001, OHCHR officials expressed concerns that the negotiation of agricultural trade rules failed to "take sufficient account of the food security of the poor and vulnerable such as poor farmers and farm workers" (OHCHR 2002b:para. 57). This focus on the plight of poor populations was consistent with the OHCHR's organizational culture and the foundational norm of the human rights regime - protecting the rights of vulnerable groups. Then High Commissioner Mary Robinson decided to seek to use her authority to put

\footnotetext{
${ }^{15}$ Interviews with WFP Directors, Deputy Directors and Executive Board Members, October 2008 and February 2009.

${ }^{16}$ Interview with WFP Senior Economist, February 2009.

${ }^{17}$ This includes the 1999 General Comment No. 12 by the Committee on Economic, Social and Cultural Rights and the 2004 Voluntary Guidelines to Support the Progressive Realization of the Right to Adequate Food in the Context of National Food Security.

${ }^{18}$ Interview with OHCHR Human Rights Officer, March 2009.
} 
the right to food onto the WTO's negotiating agenda (OHCHR 2002a). ${ }^{19}$ However, since the OHCHR lacked observer status to the WTO, Robinson did not have the right to address WTO members at meetings of the WTO General Council or its other decision-making bodies. Doing so would require a formal invitation approved by the entire WTO membership, which would have been blocked by the US, for whom Robinson was persona non grata after naming and shaming the Bush administration for its use of torture in the "war on terror". 20

Instead, in 2002, the High Commissioner chose to issue a report examining the human rights implications of agricultural trade liberalization. Reports issued by the High Commissioner differ substantially from those commonly produced by IOs in that their primary purpose is not to communicate information but to put forward formal recommendation to states that, under the procedures of the Commission on Human Rights, must be debated and voted on (Gaer and Broecker 2013). Such reports also carry considerable moral authority, as they are the main mechanism through which the High Commissioner alerts the international community to important and pressing human rights issues, and are therefore taken seriously by states, as well as NGOs and other human rights bodies (Hannum 2006). The High Commissioner was cognizant that her decision to publish a report on the agricultural trade negotiations at the WTO could prompt a backlash from states. It was highly unusual for a top UN official to comment on a "live" international trade negotiation among states. Furthermore, WTO members had already signaled that they were strongly against bringing human right considerations into the WTO, arguing that doing so would "unduly complicate" the negotiations (Petersmann 2004:607). However, the High Commissioner believed that it was consistent with her mandate and that the importance of the issue necessitated intervention by the OHCHR at the WTO (OHCHR 2002a:3-5). She did not notify states in advance of her plans to publish the report, which was released publicly by the OHCHR three months before it came before states for formal discussion at the Commission on Human Rights. ${ }^{21}$

The High Commissioner's report, entitled Globalization and its impact on the full enjoyment of human rights, offered a nuanced assessment of the relationship between agricultural trade rules and the right to food (Petersmann 2004; Lang 2011). In the report, the High Commissioner emphasized that the WTO had established a transparent, rules-based and fairer trading order, but also drew attention to the fact that trade liberalization resulted in greater vulnerability to food insecurity for certain groups (OHCHR 2002a:12-13). The report provided Robinson with a vehicle to intervene at the WTO, by declaring that WTO members had a prior legal duty as parties to human right treaties to ensure that the agricultural negotiations did not adversely impact the food security of vulnerable groups (OHCHR 2002a:5). The High Commissioner argued that:

The legal basis for adopting human rights approaches to trade liberalization is clear. All WTO members have undertaken obligations under human rights law.

\footnotetext{
${ }^{19}$ Personal communication with Mary Robinson, June 2009.

${ }^{20}$ Interview with OHCHR Senior Human Rights Officer, March 2009.

21 The report was released in January 2002 but not tabled for debate by UN members until the 58th Session of the Commission on Human Rights in April 2002.
} 
All 144 members of the WTO have ratified at least one human rights instrument ... Further, those areas of human rights law recognized as customary international law take on universal application, which means that trade rules should be interpreted as consistent with those norms and standards whatever the treaty commitments of States in trade matters. In other words, whatever the human rights treaty obligations undertaken by particular States, WTO members have concurrent human rights obligations under international law and should therefore promote and protect human rights during the negotiation and implementation of international rules on trade liberalization. (OHCHR 2002b:8)

In light of these obligations, the High Commissioner argued that it was incumbent on WTO members to adequately consider the human right to food in formulating their bargaining proposals.

Drawing on international human rights law, the High Commissioner also proposed in the report that new food security safeguards be added to the agenda of the WTO agriculture negotiations. Specifically, invoking the core human rights principle of nondiscrimination -which is set out in the International Convention on Economic, Social and Cultural Rights (ICESCR) and confers on states a legal duty to protect vulnerable groups from unlawful discrimination - the High Commissioner argued that states are required to protect the right to food of vulnerable groups harmed by agricultural trade liberalization (OHCHR 2002a:16). The High Commissioner proposed that the WTO create two new trade rules to protect the right to food in developing countries: one rule that would make protecting the food security of vulnerable groups, such as low-income and resource-poor farmers, farm laborers and rural communities, grounds for exception from trade liberalization commitments; and a second rule that would specifically promote domestic food security, such as by providing food insecure countries greater flexibility to subsidize the production of essential foodstuffs. In advocating these new rules, the High Commissioner cited governments' existing obligations under human rights treaties to respect, fulfill and promote the right to food of their citizens and those of their trading partners (OHCHR 2002a:18).

The High Commissioner's report on agricultural trade liberalization was well received by many WTO members, who appreciated its "careful and moderate tone" and balanced assessment of the benefits and costs of agricultural trade liberalization, which served to assuage concerns at the WTO that the OHCHR was anti-trade (Lang 2011:121). However, the High Commissioner's recommendations for additional food security safeguards for developing countries were viewed unfavorably by powerful agricultural exporters, such as the US, EU, Canada and Brazil, which wanted more aggressive trade liberalization.

The High Commissioner's report created uncertainty for WTO members about whether their negotiating positions could be inconsistent with their obligations under international human rights treaties. ${ }^{22}$ The prospect that the WTO negotiations could produce an outcome that contravened international human rights law was new information for WTO members, causing many trade negotiators to seek clarification from legal experts back in capitals and from the WTO secretariat. ${ }^{23}$ The High

\footnotetext{
${ }^{22}$ Multiple interviews with Trade Negotiators, 2008 and 2009.

${ }^{23}$ Interviews with WTO Senior Legal Counsellors and Deputy Director, October 2008.
} 
Commissioner's report also generated considerable interest and impact outside the WTO and was taken up among international lawyers, human rights advocates, NGOs and parliamentarians to call on the responsibility of governments to protect human rights in trade negotiations (Lang 2011).

Under Robinson's successor, Sérgio Vieira de Mello, the OHCHR intervened again at the 2003 WTO Cancun Ministerial Conference. In advance of the Ministerial, the US and EU agreed to a draft agriculture agreement that many expected would be forced on the rest of the WTO membership as a fait accompli (Hopewell 2016:80-81). OHCHR officials analyzed the draft agreement proposed by the US and EU and were concerned by the absence of adequate safeguards to protect the right to food of vulnerable groups. The deal on the table going into the Cancun Ministerial was viewed by OHCHR officials as highly unfavorable from a human rights perspective. ${ }^{24}$ In response, the OHCHR took the unprecedented action of making an "unofficial submission" directly to WTO trade ministers. Under the official procedures of the WTO, only its member states can table submissions for consideration by trade ministers at a ministerial meeting. The WTO secretariat accordingly refused to distribute the OHCHR's submission as part of the official package of ministerial documents. Instead, the OHCHR distributed its "unofficial submission" by sending copies directly to national missions to the WTO and trade ministers in capitals, as well as posting a copy on its website for the public and media.

The OHCHR's unofficial submission, entitled Trade and Human Rights, was styled as a primer "to assist policy makers who might not be familiar with the international human rights system" by providing illustrative examples of how trade liberalization could infringe on human rights (OHCHR 2003:2). Similar to the High Commissioner's 2002 report, the submission invoked the legal obligations of WTO members as parties to international human rights treaties to protect the right to food in trade negotiations. Illustrative examples included an overview of how agricultural tariff reductions could increase food security for consumers but worsen that of resource-poor farmers (OHCHR 2003:9-11). The purpose of the OHCHR's unofficial submission was to influence the politics of decision-making at the WTO. The submission was an exercise of its authority by calling on WTO members to take into account not just economic considerations but also international human rights law in the negotiations. The OHCHR's goal was to tilt the political balance in the WTO negotiations towards the inclusion of more robust food security safeguards than was preferred by powerful states, by presenting these safeguards as consistent with WTO members' obligations under international human rights treaties. The decision to present an unofficial submission to WTO members at the 2003 Cancun Ministerial was made by the High Commissioner and senior OHCHR officials, driven by their concerns that a trade deal with negative consequences for international human rights was imminent; the submission was never presented or tabled for discussion by states at the Commission on Human Rights. ${ }^{25}$

The OHCHR intervened in an effort to influence global trade rule-making by invoking international human rights treaties. The OHCHR's actions were taken independently and motivated by concerns that proposed trade rules did not sufficiently

\footnotetext{
${ }^{24}$ Interview with OHCHR Human Rights Officer, March 2009.

${ }^{25}$ Interviews with OHCHR Human Rights Officers, March and April 2009.
} 
protect the food security of vulnerable groups. OHCHR officials justified their interventions at the WTO as part of the organization's mandate to promote the right to food; however, they were cognizant that their actions were risky because the most powerful WTO members wanted to keep human rights considerations out of the agriculture negotiations. The US and other developed countries signaled their displeasure with the OHCHR's actions, both during private discussions with the High Commissioner, as well as by voting against resolutions endorsing the recommendations of the 2002 report at the Commission on Human Rights (UN 2002:471). Ultimately, the OHCHR's call for protecting the food security of vulnerable groups was incorporated by WTO members into the draft text of the proposed Doha Round agriculture agreement (WTO 2008:55).

\section{Conclusions and future research}

The article has advanced our understanding of the behavior of IOs in regime complexes by developing the concept of intervention. The extant literature on regime complexes has tended to treat IOs merely as arenas for states' cross-institutional political strategies and thus overlooked the capacity of IOs to pursue independent action. Intervention represents a novel type of behavior by IOs in regime complexes that is distinct from both cooperation and competition among IOs. The actions taken by the FAO, WFP and OHCHR secretariats to alter the trajectory of decision-making by WTO members did not involve collaboration with the WTO secretariat to achieve a joint policy or regulatory goal, nor were their actions an attempt to gain turf, members, resources or policy influence at the latter's expense. Instead, these IO secretariats intervened at the WTO with the explicit purpose of altering an anticipated decision by WTO member states. In each of the cases analyzed here, IO secretariats were prompted to intervene due to concerns that proposed WTO trade rules would have negative consequences for world food security. The FAO, WFP and OHCHR secretariats were not acting at the direction of their members states, but instead acted independently in deciding to intervene at the WTO, as well as in executing their particular intervention strategies. What is more, in all three cases, these secretariats acted with the knowledge that their interventions could potentially be viewed as inappropriate political interference in interstate negotiations, thereby exposing their organizations to the risk of backlash. As demonstrated in the analysis, this risk of backlash was significant: in the case of the WFP, states blocked its Executive Director from seeking reappointment for a second term as retribution for intervening at the WTO. This article has provided the first empirical evidence of intervention and demonstrated three different intervention strategies - mobilizing states, public shaming and invoking alternative legal frameworks employed by IOs to influence decision-making outside their organizational boundaries.

\subsection{Future research}

While the research presented in this article is exploratory and intended to demonstrate the plausibility of intervention, the study of IO intervention opens a valuable new agenda for future research on IOs and regime complexes. There is good reason to expect intervention to be a more widespread phenomenon beyond the regime complex 
for food security. Many regime complexes exhibit the basic features necessary to produce potential situations of intervention: partially overlapping authority among two or more IOs with different goals; IOs with their own preferences and capabilities for political action; and instances where decisions taken at one IO have significant consequences for other IOs in the regime complex.

Future research should seek to identify additional cases in order to expand and refine our understanding of the dynamics of IO intervention, including when and why IOs intervene, how, and to what effect. First, in order to further specify the conditions that give rise to intervention, future studies will need to expand the sample of cases, both by identifying more positive cases of intervention by different IOs across multiple regime complexes, as well as by identifying negative cases, or cases of "non-intervention" that is, cases where an IO secretariat could have intervened, or might have been expected to do so, but did not. In particular, analyzing cases where a secretariat considered intervening but decided not to (i.e., a situation in which the first three criteria for intervention identified here hold - an IO has capabilities for independent action, information about the relevant decision, and anticipates the decision to have negative consequences - but the IO chooses not to intervene) would further improve our understanding of the internal evaluation process undertaken by secretariats in deciding whether or not to engage in intervention. In addition, in the cases analyzed here, intervention was motivated primarily by the principled objectives of the intervening IO secretariat, but this is not necessarily the exclusive driver of IO intervention and analysis of additional cases could bring to light other drivers.

Second, while this article has identified three intervention strategies - mobilizing states, public shaming, and invoking alternative legal frameworks - these are unlikely to be the only strategies available to IOs in response to decisions taken elsewhere in the regime complex. As demonstrated in the cases analyzed here, IOs are creative when it comes to navigating the politics of regime complexes, and such creativity could be expected to result in the development and execution of other types of intervention strategies. Additional research analyzing other cases would be necessary to identify the full range of intervention strategies used by IOs; to specify how IOs go about selecting one strategy, or combination of strategies, over another; and to determine whether certain types of IOs are more likely to employ particular intervention strategies than others.

A final avenue for future research is to examine the effects of intervention. The case studies analyzed here have illustrated the concept of intervention and demonstrated how it may be pursued in different ways. This article has not, however, made causal claims about what determines whether intervention will be successful whether, in other words, the intervening IO will succeed in altering the anticipated decision at the target IO and preventing the outcome it views as unfavorable - or about the effectiveness of particular intervention strategies. Future research is therefore needed to specify when, or under what conditions, IO intervention is successful or not. Among other questions, are certain types of IOs more effective than others at intervening? Are certain intervention strategies more successful than others? Such analysis will require comparison of positive and negative cases - that is, cases of both successful and failed intervention - in order to further develop our understanding of the factors that contribute to the success or failure of IO intervention and thus build towards a full theory of IO intervention. 
Acknowledgements I thank three anonymous reviewers for their constructive feedback and Angela Heucher, Julie Kaarbo, Shaun Bevan, Sebastian Bödeker, Patrick Theiner, Laura Gómez-Mera, Ina Möller, Matthias Kranke, Anna Holzscheiter, Matthias Hofferberth, Amandine Orsini and Sigrid Quack for comments on earlier versions of the paper.

Availability of data and material Not relevant.

Authors' contributions Not relevant.

\section{Compliance with ethical standards}

Conflicts of interest/competing interests None.

Code availability Not relevant.

Open Access This article is licensed under a Creative Commons Attribution 4.0 International License, which permits use, sharing, adaptation, distribution and reproduction in any medium or format, as long as you give appropriate credit to the original author(s) and the source, provide a link to the Creative Commons licence, and indicate if changes were made. The images or other third party material in this article are included in the article's Creative Commons licence, unless indicated otherwise in a credit line to the material. If material is not included in the article's Creative Commons licence and your intended use is not permitted by statutory regulation or exceeds the permitted use, you will need to obtain permission directly from the copyright holder. To view a copy of this licence, visit http://creativecommons.org/licenses/by/4.0/.

\section{References}

Abbott, K. W., \& Snidal, D. (1998). Why states act through formal international organizations. Journal of Conflict Resolution, 42(1), 3-32.

Abbott, K. W., \& Snidal, D. (2010). International regulation without international government: Improving IO performance through orchestration. The Review of International Organizations, 5(3), 315-344.

Alter, K. J., \& Meunier, S. (2009). The politics of international regime complexity. Perspectives on Politics, $7(1), 13-24$.

Alter, K. J., \& Raustiala, K. (2018). The rise of international regime complexity. Annual Review of Law and Social Science, 14, 329-349.

Alvarez, J. E. (2002). The WTO as linkage machine. The American Journal of International Law, 96(1), 146158.

Barnett, M., \& Coleman, L. (2005). Designing police: Interpol and the study of change in international organizations. International Studies Quarterly, 49(4), 593-619.

Barnett, M. N., \& Finnemore, M. (2004). Rules for the world: International organizations in global politics. Ithaca: Cornell University Press.

Bauer, M. W., \& Ege, J. (2016). Bureaucratic autonomy of international organizations' secretariats. Journal of European Public Policy, 23(7), 1019-1037.

Bauer, S. (2009). The desertification secretariat: A castle made of sand. In F. Biermann \& B. Siebenhüner (Eds.), Managers of global change: The influence of international environmental bureaucracies (pp. 293-317). Cambridge: MIT Press.

Bayram, A. B., \& Graham, E. R. (2017). Financing the United Nations: Explaining variation in how donors provide funding to the UN. The Review of International Organizations, 12(3), 421-459.

Betts, A. (2013). Regime complexity and international organizations: UNHCR as a challenged institution. Global Governance, 19(1), 69-81.

Biermann, F., \& Siebenhüner, B. (Eds.). (2009). Managers of global change: The influence of international environmental bureaucracies. Cambridge: MIT Press.

Biermann, F., \& Siebenhüner, B. (2013). Problem solving by international bureaucracies. In B. Reinalda (Ed.), Routledge handbook of international organization (pp. 149-161). London and New York. 
Biermann, R., \& Koops, J. A. (2017). Studying relations among international organizations in world politics: Core concepts and challenges. In J. A. Koops \& R. Biermann (Eds.), Palgrave handbook of interorganizational relations in world politics (pp. 1-46). London: Palgrave Macmillan.

Breitmeier, H., Schwindenhammer, S., Checa, A., Manderbach, J., \& Tanzer, M. (2020). Politicized sustainability and agricultural policy: Comparing norm understandings of international organizations. Journal of Comparative Policy Analysis: Research and Practice.

Broome, A. (2008). The importance of being Earnest: The IMF as a reputational intermediary. New Political Economy, 13(2), 125-151.

Christoffersen, L. E., Bezanson, K., Lele, K., Davies, M., Perez del Castillo, C., \& Awori, T. (2008). The challenge of renewal: An independent external evaluation of the Food and Agriculture Organization. FAO: Rome.

Chwieroth, J. M. (2009). Capital ideas: The IMF and the rise of financial liberalization. Princeton: Princeton University Press.

Clapp, J. (2015). Hunger in the balance: The new politics of international food aid. Ithaca: Cornell University Press.

Costa, O. (2017). Assessing influence between international organizations. In J. A. Koops \& R. Biermann (Eds.), Palgrave handbook of inter-organizational relations in world politics (pp. 389-405). London: Palgrave Macmillan.

Davies, M. D. V. (2013). Saouma, Edouard Victor. In B. Reinalda, K. J. Kille, \& J. Eisenberg (Eds.), IO BIO: Biographical Dictionary of Secretaries-General of International Organizations.

Ege, J., Bauer, M. W., \& Wagner, N. (2019). Improving generalizability in transnational bureaucratic influence research: A (modest) proposal. International Studies Review.

Eilstrup-Sangiovanni, M. (2020). Death of international organizations. The organizational ecology of intergovernmental organizations, 1815-2015. The Review of International Organizations, 15(2), 339-370.

Elsig, M. (2010). The World Trade Organization at work: Performance in a member-driven milieu. The Review of International Organizations, 5(3), 345-363.

FAO. (1979). Report of the council of FAO: Seventy-fifth session. Rome: FAO.

FAO (1986). Statement by Mr. J.C. Vignaud. Geneva: GATT.

FAO (1987). FAO conference. Twenty-fourth session. Verbatim records of meetings of Commission I. Rome: FAO.

FAO. (1991). FAO council ninety-ninth session: Verbatim report. Rome: FAO.

FAO. (1993a). Compensation: The consolation prize. CERES: FAO Review on Agriculture and Development, $141,28-31$.

FAO. (1993b). International action relating to agricultural commodities - Interaction with international organizations. Rome: FAO.

Farsund, A. A., Daugbjerg, C., \& Langhelle, O. (2015). Food security and trade: Reconciling discourses in the food and agriculture organization and the World Trade Organization. Food Security, 7(2), 383-391.

Gaer, F. D., \& Broecker, C. L. (2013). The United Nations high commissioner for human rights: Conscience for the world. Leiden: Martinus Nijhoff Publishers.

GATT. (1987). Trade negotiations Commitee. Third meeting: 3 July 1987. Geneva: GATT.

GATT. (1988). Trade negotiations committee meeting at ministerial level. Geneva: GATT.

GATT. (1989). Summary of Main points raised at the sixteenth meeting of the negotiating group on agriculture 25-26 October 1989. Geneva: GATT.

GATT. (1990a). Framework agreement on agriculture reform programme: Draft text by the Chairman. Geneva: GATT.

GATT (1990b). Working paper submitted by Egypt, Jamaica, Morocco and Peru: Uruguay round window for net food importing developing countries. Geneva: GATT.

Gehring, T., \& Faude, B. (2014). A theory of emerging order within institutional complexes: How competition among regulatory international institutions leads to institutional adaptation and division of labor. The Review of International Organizations, 9(4), 471-498.

Gerring, J. (1999). What makes a concept good? A criterial framework for understanding concept formation in the social sciences. Polity, 31(3), 357-393.

Gómez-Mera, L. (2016). Regime complexity and global governance: The case of trafficking in persons. European Journal of International Relations, 22(3), 566-595.

Green, J. F., \& Auld, G. (2017). Unbundling the regime complex: The effects of private authority. Transnational Environmental Law, 6(2), 259-284.

Haas, P. M. (1989). Do regimes matter? Epistemic communities and Mediterranean pollution control. International Organization, 43(3), 377-403. 
Haftel, Y. Z., \& Thompson, A. (2006). The Independence of international organizations. Journal of Conflict Resolution, 50(2), 253-275.

Hall, N., \& Woods, N. (2018). Theorizing the role of executive heads in international organizations. European Journal of International Relations, 24(4), 865-886.

Hannah, E., Ryan, H., \& Scott, J. (2017). Power, knowledge and resistance: Between co-optation and revolution in global trade. Review of International Political Economy, 24(5), 741-775.

Hannum, H. (2006). Human rights in conflict resolution: The role of the Office of the High Commissioner for human rights in UN peacemaking and Peacebuilding. Human Rights Quarterly, 28(1), 1-85.

Hawkins, D. G., Lake, D. A., Nielson, D., \& Tierney, M. J. (2006). Delegation and Agency in International Organizations. Cambridge: Cambridge University Press.

Heldt, E. C., \& Schmidtke, H. (2017). Measuring the empowerment of international organizations: The evolution of financial and staff capabilities. Global Policy, 8(S5), 51-61.

Heldt, E. C., \& Schmidtke, H. (2019). Explaining coherence in international regime complexes: How the World Bank shapes the field of multilateral development finance. Review of International Political Economy, 26(6), 1160-1186.

Helfer, L. R. (2009). Regime shifting in the international intellectual property system. Perspectives on Politics, $7(01), 39-44$.

Heri, S., \& Häberli, C. (2011). Can the World Trade Organization ensure that food aid is genuine? Developing World Review on Trade and Competition, 1(1), 1-70.

Hofmann, S. C. (2019). The politics of overlapping organizations: Hostage-taking, forum-shopping and brokering. Journal of European Public Policy, 26(6), 883-905.

Holzscheiter, A. (2017). Coping with institutional fragmentation? Competition and convergence between boundary organizations in the global response to polio. Review of Policy Research, 34(6), 767-789.

Hopewell, K. (2016). Breaking the WTO: How emerging powers disrupted the neoliberal project. Stanford: Stanford University Press.

Jinnah, S. (2014). Post-treaty politics: Secretariat influence in global environmental governance. Cambridge: MIT Press.

Johnson, T. (2014). Organizational progeny: Why governments are losing control over the proliferating structures of global governance. Oxford: Oxford University Press.

Johnson, T., \& Urpelainen, J. (2012). A strategic theory of regime integration and separation. International Organization, 66(4), 645-677.

Keohane, R. O., \& Victor, D. G. (2011). The regime complex for climate change. Perspectives on Politics, 9(1), 7-23.

Khor, M. (2005). More finger pointing, less negotiation, as Ministerial gets under way. https://www.twn.my/ title2/twninfo325.htm. Accessed August 72020.

Kille, K. J. (2007). The UN secretary-general and moral authority: Ethics and religion in international leadership. Washington, D.C.: Georgetown University Press.

Knill, C., Bayerlein, L., Enkler, J., \& Grohs, S. (2018). Bureaucratic influence and administrative styles in international organizations. The Review of International Organizations, 14(1), 83-106.

Koremenos, B., Lipson, C., \& Snidal, D. (2001). The rational Design of International Institutions. International Organization, 55(4), 761-799.

Kranke, M. (2020). Exclusive expertise: The boundary work of international organizations. Review of International Political Economy, 1-24.

Kreuder-Sonnen, C., \& Zürn, M. (2020). After fragmentation: Norm collisions, interface conflicts, and conflict management. Global Constitutionalism, 9(2), 241-267.

Lall, R. (2017). Beyond institutional design: Explaining the performance of international organizations. International Organization, 71(2), 245-280.

Lang, A. (2011). World trade law after neoliberalism. Oxford: Oxford University Press.

Lebovic, J. H., \& Voeten, E. (2006). The politics of shame: The condemnation of country human rights practices in the UNCHR. International Studies Quarterly, 50(4), 861-888.

Lipson, M. (2017). Organization theory and cooperation and conflict among international organizations. In J. A. Koops \& R. Biermann (Eds.), Palgrave handbook of inter-organizational relations in world politics (pp. 67-96). London: Palgrave Macmillan UK.

Littoz-Monnet, A. (2017). Expert knowledge as a strategic resource: International bureaucrats and the shaping of bioethical standards. International Studies Quarterly, 61(3), 584-595.

Mandleson, P., \& Fisher Boel, M. (2005). Advertisement from UN agencies. (pp. 14): The financial times.

Margulis, M. E. (2013). The regime complex for food security: Implications for the global hunger challenge. Global Governance, 19(1), 53-67. 
Martin, L. L. (2006). Distribution, information, and delegation to international organizations: The case of IMF conditionality. In D. G. Hawkins, D. A. Lake, D. Nielson, \& M. J. Tierney (Eds.), Delegation and agency in international organizations (pp. 140-164). Cambridge: Cambridge University Press.

Morin, J.-F. (2020). Concentration despite competition: The organizational ecology of technical assistance providers. The Review of International Organizations, 15(1), 75-107.

Morse, J. C., \& Keohane, R. O. (2014). Contested multilateralism. The Review of International Organizations, 9(4), 385-412.

Narlikar, A. (2003). International trade and developing countries: Bargaining coalitions in the GATT and WTO. Abingdon and New York: Routledge.

Nielson, D. L., \& Tierney, M. J. (2003). Delegation to international organizations: Agency theory and World Bank environmental reform. International Organization, 57(2), 241-276.

Nielson, D. L., Tierney, M. J., \& Weaver, C. E. (2006). Bridging the rationalist-constructivist divide: Reengineering the culture of the World Bank. Journal of International Relations and Development, 9(2), 107-139.

Oberthür, S., \& Gehring, T. (2006). Institutional interaction in global environmental governance: The case of the Cartagena protocol and the World Trade Organization. Global Environmental Politics, 6(2), 1-31.

Oestreich, J. E. (2012). International organizations as self-directed actors: A framework for analysis. New York: Routledge.

OHCHR. (2002a). Globalization and its impact on the full enjoyment of human rights: Report of the high commissioner for human rights submitted in accordance with commission on human rights resolution 2001/32. Geneva: OHCHR.

OHCHR. (2002b). The right to food: Achievements and challenges. Geneva: OHCHR.

OHCHR. (2003). Human rights and trade: Submission to the 5th WTO ministerial conference. Geneva: OHCHR.

Orsini, A. (2013). Multi-forum non-state actors: Navigating the regime complexes for forestry and genetic resources. Global Environmental Politics, 13(3), 34-55.

Orsini, A., Morin, J.-F., \& Young, O. (2013). Regime complexes: A buzz, a boom, or a boost for global governance? Global Governance, 19(1), 27-39.

Pevehouse, J., Nordstrom, T., \& Warnke, K. (2004). The correlates of war 2 international governmental organizations data version 2.0. Conflict Management and Peace Science, 21(2), 101-119.

Pratt, T. (2018). Deference and hierarchy in international regime complexes. International Organization, $72(3), 561-590$.

Rabitz, F. (2014). Explaining institutional change in international patent politics. Third World Quarterly, 35(9), 1582-1597.

Ratner, S. R. (2011). Law promotion beyond law talk: The red cross, persuasion, and the Laws of war. European Journal of International Law, 22(2), 459-506.

Raustalia, K., \& Victor, D. G. (2004). The regime complex for plant genetic resources. International Organization, 58(2), 277-309.

Reinalda, B., \& Verbeek, B. (1998). Autonomous policy making by international organisations. Abingdon and New York: Routledge.

Sarfaty, G. A. (2009). Why culture matters in international institutions: The marginality of human rights at the World Bank. American Journal of International Law, 103(4), 647-683.

Seiderman, I. (2019). The UN high commissioner for human rights in the age of global backlash. Netherlands Quarterly of Human Rights, 37(1), 5-13.

Shaw, D. J. (2007). World food security: A history since 1945. London: Palgrave Macmillan.

Sikkink, K. (1993). Human rights, principled issue-networks, and sovereignty in Latin America. International Organization, 47(3), 411-441.

Steinberg, R. H. (2002). In the shadow of law or power? Consensus-based bargaining and outcomes in the GATT/WTO. International Organization, 56(02), 339-374.

Tallberg, J., Sommerer, T., Squatrito, T., \& Jönsson, C. (2013). The opening up of international organizations: Transnational access in global governance. Cambridge: Cambridge University Press.

UN (1994). Resolution A/RES/48/141. New York: UN.

UN. (2002). Commission on human rights: Report on the fifty-eight session (Supplement 3). New York and Geneva: UN.

Vabulas, F., \& Snidal, D. (2013). Organization without delegation: Informal intergovernmental organizations (IIGOs) and the spectrum of intergovernmental arrangements. The Review of International Organizations, $8(2), 193-220$. 
Walch, K. S. (2003). Feminist ideas on cooperation and self-interest for international relations. In M. A. Tétreault \& R. L. Teske (Eds.), Partial truths and the politics of community (Vol. 2, pp. 161-179). Columbia: University of South Carolina Press.

Weaver, C. (2008). Hypocrisy trap: The World Bank and the poverty of reform. Princeton: Princeton University Press.

Weaver, C., \& Nelson, S. C. (2016). Organizational culture. In J. K. Cogan, I. Hurd, \& I. Johnstone (Eds.), The Oxford handbook of international organizations (pp. 920-939). Oxford: Oxford University Press.

WFP. (2005a). Statement by the deputy executive director of the WFP. Rome: WFP.

WFP. (2005b). Statement by the Execuitve director of the WFP. Rome: WFP.

Will WTO's Trade Negotiators Take the Food Out of Their Mouths? (2005 12). The Financial Times, p. 15.

World Bank. (1986). World development report. Washington, DC: World Bank.

WTO. (1994). Agreement on agriculture. Geneva: GATT.

WTO. (2005). Agriculture negotiations: Key issues to be addressed by 31 July 2005. Geneva: WTO.

WTO (2008). Revised draft modalities for agriculture. Geneva: WTO.

Xu, Y.-C., \& Weller, P. (2008). 'To be, but not to be seen': Exploring the impact of international civil servants. Public Administration, 86(1), 35-51.

Zelli, F., Möller, I., \& Asselt, H. v. (2017). Institutional complexity and private authority in global climate governance: The cases of climate engineering, REDD+ and short-lived climate pollutants. Environmental Politics, 26(4), 669-693.

Zhao, J. (forthcoming). The role of international organizations in preventing conflicts between the SPS agreement and the Cartagena protocol on biosafety. Review of European, Comparative \& International Environmental Law.

Publisher's note Springer Nature remains neutral with regard to jurisdictional claims in published maps and institutional affiliations.

\section{Affiliations}

\section{Matias E. Margulis ${ }^{1,2}$}

1 School of Public Policy and Global Affairs, University of British Columbia, C.K. Choi Building 373, 1855 West Mall, Vancouver, British Columbia V6T 1Z2, Canada

2 Faculty of Land and Food Systems, University of British Columbia, 131 - 2357 Main Mall, H. R. MacMillan Building, Vancouver BC V6T 1Z4, Canada 